\title{
Target Extra Nodal Tumor Identification
}

National Cancer Institute

\section{Source}

National Cancer Institute. Target Extra Nodal Tumor Identification. NCI Thesaurus. Code C103442.

The identification of a target tumor located outside of or independent of the lymph node. 